\title{
17a-ethynylestradiol (EE2) limits the impact of ibuprofen upon respiration by streambed biofilms in a sub-urban stream
}

\author{
Peter McClean ${ }^{1} \cdot$ William Ross Hunter ${ }^{1,2}$ (D) \\ Received: 24 March 2020 / Accepted: 10 July 2020 / Published online: 17 July 2020 \\ (C) The Author(s) 2020
}

\begin{abstract}
Pharmaceutical compounds such as the non-steroidal anti-inflammatory drug ibuprofen and the artificial estrogen $17 \alpha$ ethynylestradiol (EE2) are contaminants of emerging concern in freshwater systems. Globally, human pharmaceutical use is growing by around $\sim 3 \%$ per year; yet, we know little about how interactions between different pharmaceuticals may affect aquatic ecosystems. Here, we test how interactions between ibuprofen and EE2 affect the growth and respiration of streambed biofilms. We used contaminant exposure experiments to quantify how these compounds affected biofilm growth (biomass), respiration, net primary production (NPP) and gross primary production (GPP), both individually and in combination. We found no effects of either ibuprofen or EE2 on biofilm biomass (using ash-free dry mass as a proxy) or gross primary production. Ibuprofen significantly reduced biofilm respiration and altered NPP. Concomitant exposure to EE2, however, counteracted the inhibitory effects of ibuprofen upon biofilm respiration. Our study, thus, demonstrates that interactions between pharmaceuticals in the environment may have complex effects upon microbial contributions to aquatic ecosystem functioning.
\end{abstract}

Keywords $17 \alpha$-ethynylestradiol $\cdot$ Biofilm $\cdot$ EE2 $\cdot$ Ibuprofen $\cdot$ Microbial metabolism $\cdot$ Pharmaceuticals and personal care products

\section{Introduction}

Human pharmaceuticals and personal care products (PPCPS) are contaminants of emerging concern within the environment (Rosi-Marshall and Royer 2012; Gaston et al. 2019). Since the year 2000, pharmaceutical use has grown by approximately $3 \%$ per year globally and this is predicted to increase further as human populations grow (Van Boeckel et al. 2014). Removal of PPCPs via waste-water treatment plants (WWTPs) is inefficient leading to the constant release of low doses of compounds such as non-steroidal anti-inflammatory drugs (NSAIDs) (e.g. ibuprofen), antimicrobial compounds (e.g.

Responsible Editor: Diane Purchase

Electronic supplementary material The online version of this article (https://doi.org/10.1007/s11356-020-10096-5) contains supplementary material, which is available to authorized users.

William Ross Hunter

Billy.Hunter@afbini.gov.uk

1 School of Geography and Environmental Science, University of Ulster, Coleraine BT52 1SA, UK

2 Fisheries and Aquatic Ecosystems Branch, Northern Ireland Agri-Food and Bioscience Institute, Belfast BT9 5PX, UK triclosan and trimethoprim) and artificial estrogens (e.g. $17 \alpha$-ethynylestradiol) into the aquatic environment (Gros et al. 2007; Álvarez-Muñoz et al. 2015; Archer et al. 2017). This is potentially problematic because these compounds are specifically designed specifically to produce physiological effects within an organism, at ultra-low (nano-molar) concentrations (Rosi-Marshall and Royer 2012; Van Boeckel et al. 2014; Álvarez-Muñoz et al. 2015). Eco-toxicological studies reveal that PPCPs at environmental concentrations can have significant physiological effects on both aquatic fauna and microorganisms, with the potential to disrupt aquatic ecosystem functioning altering carbon and nutrient cycling, and negatively affect water quality (Jobling et al. 2003; Hernando et al. 2006; Rosi-Marshall et al. 2013; Drury et al. 2013; Żur et al. 2018; Gallagher and Reisinger 2020).

In headwater streams, aquatic biofilms attached to the streambed represent the dominant mode of microbial life (Besemer et al. 2012; Battin et al. 2016). Biofilms, composed of consortia of bacteria and unicellular eukaryotic algae bound within a complex matrix of extracellular polymeric substances (EPS), play a key role in the functioning of fluvial ecosystems, controlling both the transport and degradation of organic matter within a stream (Battin et al. 2016). Rosi-Marshall et al. (2013) revealed that aquatic PPCPs such as caffeine, 
cimetidine, ciprofloxacin, diphenhydramine, metformin and ranitidine had negative effects upon biofilm growth, respiration and community composition. PPCPs, however, are diverse group of chemicals, which may interact with each other in a multitude of different, and often-unexpected ways (RosiMarshall et al. 2013; Gerbersdorf et al. 2015; Gaston et al. 2019; Robson et al. 2020). Consequently, a mechanistic understanding of the interactions between different PPCPs is needed if we are to fully understand their environmental impacts.

Within the broad spectrum of PPCPs, the non-steroidal anti-inflammatories (NSAIDs), such as ibuprofen, and artificial estrogens, such as $17 \alpha$-ethynylestradiol, represent some of the most commonly detected compounds in aquatic systems (Álvarez-Muñoz et al. 2015; Gaston et al. 2019). NSAIDs are known to have antimicrobial properties, with ibuprofen exhibiting potential as a biofilm control agent (Reśliński et al. 2015; Shah et al. 2018; Żur et al. 2018; Oliveira et al. 2019). Conversely, artificial estrogens and other endocrine disruptors may adsorb onto microbial biofilms facilitating their biological degradation (Writer et al. 2012; Zhang et al. 2014; Adeel et al. 2017). There are currently no known therapeutic interactions between NSAIDs and artificial estrogens in animal systems. The fact that these compounds elicit different microbial responses, however, suggests that there may be potential for interactions between NSAIDs and artificial estrogens to affect the growth and metabolism of aquatic microorganisms. Here, we present the first data on how interactions between ibuprofen and $17 \alpha$ ethynylestradiol (hereafter, EE2) affect the growth and respiration of streambed biofilms. We conducted in situ contaminant exposure experiments, following Costello et al. (2016), to test how chronic exposure to ibuprofen, and EE2, both individually and in combination, affected streambed biofilm growth, primary production, and respiration.

\section{Materials and methods}

All experiments were carried out between the 30th November 2018 and the 22nd January 2019 in the Ballysally Blagh (latitude: $55^{\circ} 08^{\prime} 45.1^{\prime \prime} \mathrm{N}$, longitude: $6^{\circ} 40^{\prime} 18.0^{\prime \prime} \mathrm{W}$ ), a groundwater fed second-order stream. The Ballysally Blagh is a tributary of the lower River Bann (Northern Ireland), draining a mixed agricultural (consisting of $21.9 \%$ arable, $55.9 \%$ grassland, $13.7 \%$ heathland, $1.9 \%$ woodland) and urban (7.3\%) catchment of $14.2 \mathrm{~km}^{2}$. The mean volumetric rate for water flow in the Ballysally Blagh is $0.21( \pm 0.27) \mathrm{m}^{3} \mathrm{~s}^{-1}$, measured at a V-shaped weir (National River Flow Archive. 2019) and the stream is defined as eutrophic, with dissolved nitrate concentrations ranging between 1.37 and $14.15 \mathrm{ml} \mathrm{l}^{-1}$ and soluble reactive phosphorus concentrations between 0.033 and $0.4 \mathrm{mg}^{-1}$. Water temperature at the study site was recorded at 1-h intervals throughout the experiment using a HOBO MX2204 Bluetooth temperature logger. Temperatures ranged between 9.35 and $5.16^{\circ} \mathrm{C}$, with a mean temperature of $7.72( \pm$ $0.85)^{\circ} \mathrm{C}$ recorded over the study period.

Contaminant exposure experiments were conducted following Costello et al. (2016). Briefly, forty $120-\mathrm{ml}$ screw cap sample pots were filled with $2 \%$ agar, of which ten were spiked with a fixed $0.5 \mathrm{mmol}^{-1}$ concentration of ibuprofen, ten with a fixed $0.5 \mathrm{mmol}^{-1}$ concentration of EE2, ten spiked with fixed $0.5 \mathrm{mmol} \mathrm{l}^{-1}$ concentrations of both ibuprofen and EE2, and ten received no pharmaceutical treatment (control). Both ibuprofen and EE2 have relatively low solubility in water (21 $\mathrm{mg}^{-1}$ and $3.6 \mathrm{mg}^{-1}$, respectively). As such, stock solutions for each pharmaceutical treatment were made up by dissolving $159 \mathrm{mg}$ of ibuprofen (Sigma-Aldrich, Product No. I4883), 105 mg of EE2 (Sigma-Aldrich, Product No. E4876) or both in $11 \mathrm{ml}$ of $70 \%$ ethanol. One-millilitre aliquots of the stock solution were then used to dose each contaminant exposure experiment and the control treatments receiving a 1-ml aliquot of $70 \%$ ethanol. Pre-combusted Whatman ${ }^{\circledR} 45 \mathrm{~mm}$ GF/F filters were placed onto of the solid agar and secured using the screw cap, to provide a substratum for streambed biofilm colonization. Contaminant exposure experiments were then secured to 4-l-shaped metal bars $(l=1000 \mathrm{~mm}$; $w=50 \mathrm{~mm} ; d=50 \mathrm{~mm}$ ) and deployed at $10 \mathrm{~cm}$ depth, in an area of turbulent flow (riffle) within the stream.

Environmental chambers were assembled from two Curry's Essentials ${ }^{\circledR}$ C61CF13 chest freezers, with the power source re-routed through Inkbird ITC-308 Digital Temperature Controller used to override the freezers internal thermostat. A single Tetra HT50 $(50 \mathrm{~W})$ aquarium heater was also attached to the Inkbird temperature controller of each unit to help stabilise the internal temperature. Two NICREWplanted aquarium LED strip lights were attached to the lid, providing a source of photosynthetically active radiation ($106.0 \mu \mathrm{mol} \mathrm{m}{ }^{-2} \mathrm{~s}^{-1}$, measured using an Apogee Instruments Photosynthetically Active Radiation Meter). Environmental chambers were filled with 201 of streamwater and the internal temperatures set to $7.7^{\circ} \mathrm{C}$. The contaminant exposure experiments were left in situ for 54 days, after which they were recovered from the stream, directly placed into one of the environmental chambers and allowed to acclimate over $24 \mathrm{~h}$. During the acclimation period, each mesocosm was aerated using a Aqualine Hailea Aco-9630.

After the acclimation period, biofilm respiration and gross primary production were determined by changes in oxygen consumption by enclosing each contaminant exposure experiment into a sealed transparent Perspex ${ }^{\circledR}$ push core (height $=$ $30 \mathrm{~cm}$, internal diameter $=7 \mathrm{~cm}$ ) chambers, containing 11 of sterile-filtered streamwater and held at $7.7{ }^{\circ} \mathrm{C}$ in one of the environmental chambers (Bott et al. 1978; Fellows et al. 2006). Biofilm respiration (R) was quantified by measuring the change in oxygen concentrations over a 1 -h period 
(oxygen consumption in darkness (PAR $\sim 0.0 \mu \mathrm{mol} \mathrm{m} \mathrm{m}^{-2} \mathrm{~s}^{-1}$ ) using a Hach Sension 6 dissolved oxygen meter. Biofilm net primary productivity (NPP) was then quantified by measuring the change in oxygen concentration over a one 1-h period, under artificial illumination (PAR $\sim 106.0 \mu \mathrm{mol} \mathrm{m}^{-2} \mathrm{~s}^{-1}$ ). Biofilm gross primary productivity (GPP) by the biofilms was then calculated from NPP and R as

$$
\mathrm{GPP}=\mathrm{NPP}-\mathrm{R}
$$

In cases where NPP was more negative than R (indicating greater oxygen consumption under artificial illumination), the baseline for GPP defaulted to zero.

Microbial biomass within each contaminant exposure experiment was quantified as ash-free dry mass of the GF/F filters. These were dried for $48 \mathrm{~h}$ at $65{ }^{\circ} \mathrm{C}$ and then subsequently combusted at $550{ }^{\circ} \mathrm{C}$ for $2 \mathrm{~h}$. We estimated the daily dose of the pharmaceuticals delivered within each treatment following Costello et al. (2016), assuming that ibuprofen and EE2 doses were proportional to the agar mass lost.

All data are available in the supplementary information. Data analyses were conducted in the $\mathrm{R}$ statistical computing environment using the base and ggplot 2 packages ( $\mathrm{R}$ Development Core Team. 2009; Wickham 2016). We tested for independent and combined effects of ibuprofen and EE2 upon microbial biomass (ash-free dry weight), respiration and NPP and GPP using two-way analysis of variance (ANOVA). Post hoc testing of significant interactions was conducted using Tukey's test for honest significant difference. All data were visually explored, to ensure they conformed to the assumptions of normality and homoscedasticity, following Zuur et al. (2010). Microbial biomass data were $\log _{10}$ transformed to ensure the residuals of the ANOVA model conformed to a normal distribution.

\section{Results}

Using ash-free dry mass as a proxy for microbial biomass, we detected no significant effects $(p>0.05)$ of pharmaceutical exposure upon microbial biofilm growth (Fig. 1A; Table 1a). We detected a significant interaction $(p<0.001$; $\mathrm{df}=1 ; F=18.75$ ) between ibuprofen and EE2 affecting microbial respiration (Fig. 1B; Table 1b). Exposure to ibuprofen alone inhibited microbial oxygen consumption by $\sim 38 \%$, whilst exposure to EE2 alone resulted in a slight (nonsignificant) increase in oxygen consumption of $\sim 5 \%$. In combination, EE2 counteracted the inhibitory effect of ibuprofen upon of microbial respiration, resulting in no significant change in respiration relative to the control. Biofilm NPP was negative in all treatments, with ibuprofen exposure resulting in a significant decrease in oxygen consumption $(p=0.009 ; \mathrm{df}=1 ; F=7.483)$, reflecting the effect on biofilm respiration (Fig. 1C; Table 1c). Across all treatments, GPP was close to zero, with no significant effects $(p>0.05)$ of either ibuprofen or EE2. We did, however, detect a nonsignificant increase in oxygen production by biofilms exposed to both ibuprofen and GPP (Fig. 1D; Table 1d).

\section{Discussion}

Our study demonstrates that interactions between the NSAID ibuprofen and the artificial estrogen EE2 have a significant effect upon the streambed biofilm respiration. Specifically, concomitant exposure to both ibuprofen and EE2 reduced the depressive effect of ibuprofen upon biofilm respiration. Ibuprofen is known to have antimicrobial properties and has been reported to inhibit biofilm formation by both Staphylococcus aureus and Escherichia coli (Reśliński et al. 2015; Shah et al. 2018; Oliveira et al. 2019). It is, therefore, unsurprising that ibuprofen inhibited microbial respiration within the streambed biofilms. EE2 has been observed to adsorb to microbial biofilms (Writer et al. 2012) where it can then be used by the resident microorganisms as an organic matter source (Stumpe and Marschner 2009; Ribeiro et al. 2010). Consequently, biofilms have been proposed as a tool for the removal of artificial estrogens and other endocrine disruptors within wastewater treatment facilities (Pieper and Rotard 2011). The presence of EE2 as an energy source may, therefore, counteract the inhibitory effects of ibuprofen (Combalbert and Hernandez-Raquet 2010), whilst sorption of EE2 to the biofilm matrix may protect the microbial cells by reducing the space available onto which ibuprofen molecules may bind (Writer et al. 2012; Zhang et al. 2014). These mechanisms, however, remain speculative and require further investigation within controlled laboratory experiments.

The negative NPP within the experiment suggests that our biofilms were heterotrophic, relying on organic matter from the surrounding environment to provide energy and nutrients for biofilm growth. The significant effects of ibuprofen upon NPP, therefore, provide further evidence of this specific PPCP that inhibits heterotrophic metabolism in streambed biofilms. Autotrophic activity was low, within our study, limiting our ability to infer how either ibuprofen or EE2 affects the algal component within our biofilms. Nevertheless, the nonsignificant increase in GPP within biofilms exposed to both pharmaceuticals further suggests that EE2 may mediate microbial response ibuprofen exposure. This experiment was, however, conducted during the winter, when algal growth within streambed biofilms is typically low (e.g. Duncan and Blinn 1989; Francoeur et al. 1999). To adequately test how interactions between ibuprofen and EE2 affect autotrophic biofilms requires repetition of the study during spring or summer, when longer day length is likely to promote higher algal growth at the streambed. 
Fig. 1 Effects of ibuprofen $(\vartheta)$ and $17 \alpha$-ethynylestradiol (ㅇ) upon the $\mathbf{A}$ biomass (ash-free dry weight), $\mathbf{B}$ respiration and $\mathbf{C}$ net primary production and $\mathbf{D}$ gross primary production of cultured streambed biofilms. Significance levels: $* * * p<0.001 ; * * p<0.01$; ${ }^{*} p<0.05 ; \mathrm{N} / \mathrm{S} p>0.05$. Where significant interactions were identified, groups labelled with the same lowercase letter are not significantly different $(p>0.05$; Tukey's tests)
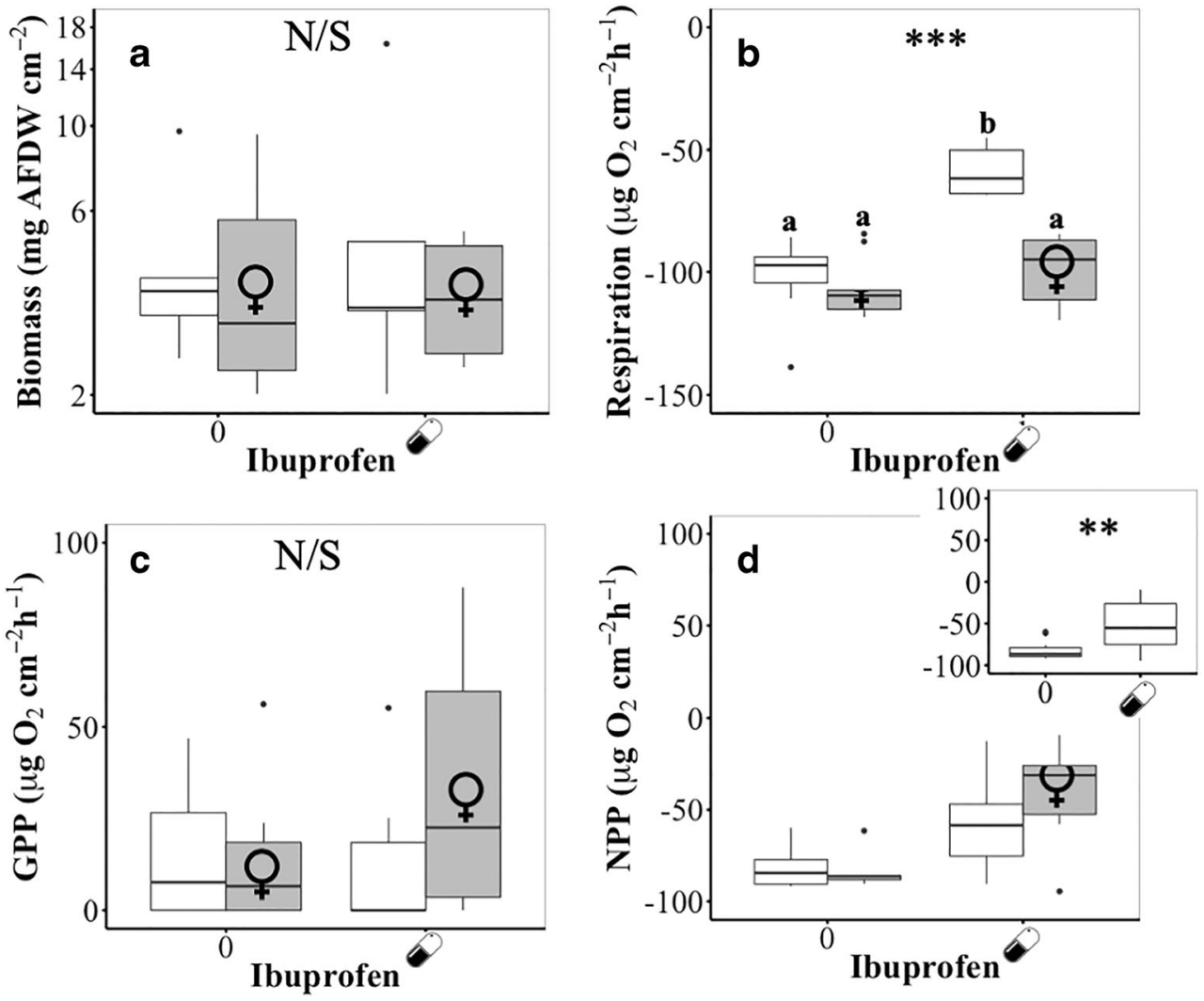

Table 1 ANOVA summary tables of the effects of ibuprofen and EE2 upon (a) biomass (ash-free dry weight), (b) respiration, (c) net primary production and (d) gross primary production of cultured streambed biofilms

$\begin{array}{lllll}d f & \text { SS } & \text { MS } & F & p\end{array}$

(a) Biomass (ash-free dry weight)

$\begin{array}{lrrrrr}\text { Ibuprofen } & 1 & 0.001 & 0.00086 & 0.008 & 0.931 \\ \text { EE2 } & 1 & 0.006 & 0.00586 & 0.051 & 0.822 \\ \text { Ibuprofen: EE2 } & 1 & 0.151 & 0.15142 & 1.331 & 0.256 \\ \text { Residuals } & 36 & 4.097 & 0.11379 & & \end{array}$

(b) Respiration

$\begin{array}{lrrrrr}\text { Ibuprofen } & 1 & 6482 & 6482 & 41.13 & <0.001 \\ \text { EE2 } & 1 & 5085 & 5085 & 32.26 & <0.001 \\ \text { Ibuprofen: EE2 } & 1 & 2952 & 2952 & 18.73 & <0.001 \\ \text { Residuals } & 36 & 5674 & 158 & & \end{array}$

(c) Net primary production

\begin{tabular}{lrrrrr} 
Ibuprofen & 1 & 7546 & 7545.8 & 7.483 & 0.009 \\
EE2 & 1 & 408 & 408.1 & 0.405 & 0.528 \\
Ibuprofen: EE2 & 1 & 38 & 38.2 & 0.038 & 0.847 \\
Residuals & 36 & 36,303 & 1008.4 & & \\
$\begin{array}{l}\text { (d) Gross primary } \\
\text { Ibroduction }\end{array}$ & & & \\
EE2 & 1 & 931.5 & 931.46 & 1.737 & 0.196 \\
Ibuprofen: EE2 & 1 & 1201.0 & 1200.96 & 2.240 & 0.143 \\
Residuals & 36 & 1607.4 & 1607.40 & 2.998 & 0.092 \\
\hline
\end{tabular}

Given ibuprofen's potential as a biofilm control agent (Reśliński et al. 2015; Shah et al. 2018; Żur et al. 2018; Oliveira et al. 2019), we were surprised to observe that it had no effect upon biofilm biomass within our experiments. This, however, may reflect the development of microbial resistance to anthropogenic stressors such as pharmaceuticals in agricultural and urban catchments to (e.g. Drury et al. 2013; Cai et al. 2016; Qu et al. 2017; Roberto et al. 2018). Furthermore, siltation of fine particulate matter may affect the accuracy of ash free dry mass as a measure of biomass in urban and agricultural streams. This leads us to suggest that complimentary analysis of specific microbial biomarkers, such as polar lipid fatty acids (Middelburg et al. 2000; Frostegård et al. 2011; Hunter et al. 2012, 2013) and extracellular polysaccharide quantification (Fish et al. 2017; Grzegorczyk et al. 2018), may provide further insight how these pharmaceutical may affect biofilm biomass and structure.

Within this short paper, we demonstrate that interactions between NSAIDs and artificial estrogens could have important implications for aquatic ecosystem functioning during the winter, when lower water temperatures limit microbial activity within streambed biofilms (Ylla et al. 2012). Whilst the doses of ibuprofen and EE2 within our study appear high, they are broadly comparable with doses used in many other contaminant exposure experiments (Drury et al. 2013; Rosi-Marshall et al. 2013; Rosi et al. 2018; Gallagher and Reisinger 2020). 
Our experiment, thus, provides a reasonably realistic insight into of how interactions between these two PPCPs affect aquatic microbial activity.

Our study supports a growing body of evidence suggesting that PPCPs represent a major threat to ecosystem functioning in many streams and rivers (Jobling et al. 2003; Hernando et al. 2006; Gros et al. 2007; Rosi-Marshall and Royer 2012; Rosi-Marshall et al. 2013; Álvarez-Muñoz et al. 2015; Ruhí et al. 2016; Archer et al. 2017). Interactions between PPCPs and their effects within the environment are potentially complex and mediated by changes in environmental context (RosiMarshall et al. 2013; Rosi et al. 2018; Gallagher and Reisinger 2020). Future studies need to investigate how the interactions between different PPCPs affect aquatic microbial communities under different regimes of temperature, aquatic chemistry and ecological community structure. This demands the design of field-based contaminant exposure experiments that test the interactions between a range of PPCPs both within and between freshwater catchments. Here, we also highlight the need to identify what underlying biochemical mechanisms determine how interactions between different PPCPs affect aquatic microbial processes.

Acknowledgments This work was completed by PMcC during his final year undergraduate research project, supervised by WRH. It was funded through start-up funds provided to WRH by the University of Ulster's School of Geography and Environmental Science. We acknowledge fieldwork assistance by Ashley Williamson, and technical support in the lab from Peter Devlin and Hugo McGrogan.

Data availability All data related to this publication are available as a supplementary data file alongside this paper.

\section{Compliance with ethical standards}

Conflict of interest The authors declare that they have no conflict of interest.

Open Access This article is licensed under a Creative Commons Attribution 4.0 International License, which permits use, sharing, adaptation, distribution and reproduction in any medium or format, as long as you give appropriate credit to the original author(s) and the source, provide a link to the Creative Commons licence, and indicate if changes were made. The images or other third party material in this article are included in the article's Creative Commons licence, unless indicated otherwise in a credit line to the material. If material is not included in the article's Creative Commons licence and your intended use is not permitted by statutory regulation or exceeds the permitted use, you will need to obtain permission directly from the copyright holder. To view a copy of this licence, visit http://creativecommons.org/licenses/by/4.0/.

\section{References}

Adeel M, Song S, Wang Y, Francis D, Yang Y (2017) Environmental impact of oestrogens on human, animal and plant life: a critical review. Environ Int 99:107-119
Álvarez-Muñoz D, Rodríguez-Mozaz S, Maulvault AL, Tediosi A, Fernández-Tejedor M, Van den Heuvel F, Kotterman M, Marques A, Barceló D (2015) Occurrence of pharmaceuticals and endocrine disrupting compounds in macroalgae, bivalves, and fish from coastal areas in Europe. Environ Res 143:56-64

Archer E, Petrie B, Kasprzyk-Hordern B, Wolfaardt GM (2017) The fate of pharmaceuticals and personal care products (PPCPs), endocrine disrupting contaminants (EDCs), metabolites and illicit drugs in a WWTW and environmental waters. Chemosphere 174:437-446

Battin TJ, Besemer K, Bengtsson MM, Romani AM, Packmann AI (2016) The ecology and biogeochemistry of stream biofilms. Nat Rev Microbiol 14:251-263

Besemer K, Peter H, Logue JB, Langenheder S, Lindstrom ES, Tranvik LJ, Battin TJ (2012) Unraveling assembly of stream biofilm communities. ISME J 6:1459-1468

Bott TL, Brock JT, Cushing CE, Gregory SV, King D, Petersen RC (1978) A comparison of methods for measuring primary productivity and community respiration in streams. Hydrobiologia 60:3-12

Cai W, Li Y, Wang P, Niu L, Zhang W, Wang C (2016) Revealing the relationship between microbial community structure in natural biofilms and the pollution level in urban rivers: a case study in the Qinhuai River basin, Yangtze River Delta. Water Sci Technol 74: 1163-1176. https://doi.org/10.2166/wst.2016.224

Combalbert S, Hernandez-Raquet G (2010) Occurrence, fate, and biodegradation of estrogens in sewage and manure. Appl Microbiol Biotechnol 86:1671-1692. https://doi.org/10.1007/s00253-0102547-x

Costello DM, Rosi-Marshall EJ, Shaw LE, Grace M, Kelly JJ (2016) A novel method to assess effects of chemical stressors on natural biofilm structure and function. Freshwat Biol 61:2129-2140. https:// doi.org/10.1111/fwb.12541

Drury B, Scott J, Rosi-Marshall EJ, Kelley JJ (2013) Triclosan exposure increases triclosan resistance and influences taxonomic composition of benthic bacterial communities. Environ Sci Technol 47:89238930

Duncan SW, Blinn DW (1989) Importance of physical variables on the seasonal dynamics of epilithic algae in a highly shaded canyon stream. J Phycol 25:455-461. https://doi.org/10.1111/j.1529-8817. 1989.tb00250.x

Fellows CS, Clapcott JE, Udy JW, Bunn SE, Harch BD, Smith MJ, Davies PM (2006) Benthic metabolism as an indicator of stream ecosystem health. Hydrobiologia 572:71-87

Fish K, Osborn AM, Boxall JB (2017) Biofilm structures (EPS and bacterial communities) in drinking water distribution systems are conditioned by hydraulics and influence discolouration. Sci Total Environ 593-594:571-580

Francoeur SN, Biggs BJF, Smith RA, Lowe RL (1999) Nutrient limitation of algal biomass accrual in streams: seasonal patterns and a comparison of methods. J N Am Benthol Soc 18(2):242-260

Frostegård A, Tunlid A, Bååth E (2011) Use and misuse of PLFA measurements in soils. Soil Biol Biochem 43:1621-1625

Gallagher MT, Reisinger AJ (2020) Effects of ciprofloxacin on metabolic activity and algal biomass of urban stream biofilms. Sci Total Environ 706:135728. https://doi.org/10.1016/j.scitotenv.2019. 135728

Gaston L, Lapworth DJ, Stuart M, Arnscheidt J (2019) Prioritization approaches for substances of emerging concern in groundwater: a critical review. Environ Sci Technol 53:6107-6122

Gerbersdorf SU, Cimatoribus C, Class H, Engesser K, Helbich S, Hollert H, Lange C, Kranert M, Metzger J, Nowak W, Seiler T, Steger K, Steinmetz H, Wieprecht S (2015) Anthropogenic trace compounds (ATCs) in aquatic habitats: research needs on sources, fate, detection and toxicity to ensure timely elimination strategies and risk management. Environ Int 79:85-105 
Gros M, Petrović M, Barcelo D (2007) Wastewater treatment plants as a pathway for aquatic contamination by pharmaceuticals in the Ebro river basin (northeast Spain). Environ Toxicol Chem 26:1553-1562

Grzegorczyk M, Pogorzelski SJ, Pospiech A, Boniewicz-Szmyt K (2018) Monitoring of marine biofilm formation dynamics at submerged solid surfaces with multitechnique sensors. Front Mar Sci 5:363

Hernando MD, Mezcua M, Fernández-Alba AR, Barceló D (2006) Environmental risk assessment of pharmaceutical residues in wastewater effluents, surface waters and sediments. Talanta 69:334-342

Hunter WR, Veuger B, Witte U (2012) Macrofauna regulate heterotrophic bacterial carbon and nitrogen incorporation in low-oxygen sediments. ISME J 6:2140-2151

Hunter WR, Jamieson A, Huvenne VAI, Witte U (2013) Sediment community responses to marine vs. terrigenous organic matter in a submarine canyon. Biogeosciences. 10:67-80

Jobling S, Casey D, Rodgers-Gray T, Oehlmann J, Schulte-Oehlmann U, Pawlowski S, Baunbeck T, Turner AP, Tyler CR (2003) Comparative responses of molluscs and fish to environmental estrogens and an estrogenic effluent. Aquat Toxicol 65:205-220

Middelburg JJ, Barranguet C, Boschker HTS, Herman PMJ, Moens T, Heip CHR (2000) The fate of intertidal microphytobenthos carbon: an in situ ${ }^{13}$ C-labeling study. Limnol Oceanogr 45:1224-1234

National River Flow Archive (2019) Station 203050: Ballysally Blagh at University of Ulster. https://nrfa.ceh.ac.uk/data/station/spatial/ 203050

Oliveira IM, Borges A, Borges F, Simões M (2019) Repurposing ibuprofen to control Staphylococcus aureus biofilms. Eur J Med Chem 166:197-205

Pieper C, Rotard W (2011) Investigation on the removal of natural and synthetic estrogens using biofilms in continuous flow biofilm reactors and batch experiments analysed by gas chromatography/mass spectrometry. Water Res 45:1105-1114

Qu X, Ren Z, Zhang H, Zhang M, Zhang Y, Liu X, Peng W (2017) Influences of anthropogenic land use on microbial community structure and functional potentials of stream benthic biofilms. Sci Rep 7: 15117. https://doi.org/10.1038/s41598-017-15624-x

R Development Core Team (2009) R: A language and environment for statistical computing

Reśliński A, Dábrowiecki S, Głowacka K (2015) The impact of diclofenac and ibuprofen on biofilm formation on the surface of polypropylene mesh. Hernia 19:179-185

Ribeiro AR, Carvalho MF, Afonso CMM, Tiritan ME, Castro PML (2010) Microbial degradation of $17 \beta$-estradiol and $17 \alpha$ ethinylestradiol followed by a validated HPLC-DAD method. J Environ Sci Health B 45:265-273

Roberto AA, Van Gray JB, Leff L (2018) Sediment bacteria in an urban stream: spatiotemporal patterns in community composition. Water Res 134:359-369

Robson SV, Rosi EJ, Richmond EK, Grace MR (2020) Environmental concentrations of pharmaceuticals alter metabolism, denitrification, and diatom assemblages in artificial streams. Freshwat Sci 39:256267. https://doi.org/10.1086/708893

Rosi EJ, Bechtold HA, Snow D, Rojas M, Reisinger AJ, Kelly JJ (2018) Urban stream microbial communities show resistance to pharmaceutical exposure. Ecosphere 9:e02041

Rosi-Marshall EJ, Royer TV (2012) Pharmaceutical compounds and ecosystem function: an emerging research challenge for aquatic ecologists. Ecosystems. 15:867-880

Rosi-Marshall EJ, Kincaid DWL, Bechtold H, Royer TV, Rojas M, Kelly JJ (2013) Pharmaceuticals suppress algal growth and microbial respiration and alter bacterial communities in stream biofilms. Ecol Appl 23:583-593

Ruhí A, Acuña A, Barceló D, Huerta B, Mor J, Rodríguez-Mozaz S, Sabater S (2016) Bioaccumulation and trophic magnification of pharmaceuticals and endocrine disruptors in a Mediterranean river food web. Sci Total Environ 540:250-259

Shah PAL, Marshall-Batty KR, Smolen JA, Tagaev JA, Chen Q, Rodesney CA, Le HH, Gordon VD, Greenberg DE, Cannon CL (2018) Antimicrobial activity of ibuprofen against cystic fibrosisassociated gram-negative pathogens. Antimicrob Agents Chemother 62:e01574-e01517

Stumpe B, Marschner B (2009) Factors controlling the biodegradation of $17 \beta$-estradiol, estrone and $17 \alpha$-ethinylestradiol in different natural soils. Chemosphere 74:556-562

Van Boeckel TP, Gandra S, Ashok A, Caudron Q, Grenfell BT, Levin SA, Laxminarayan R (2014) Global antibiotic consumption 2000 to 2010: an analysis of national pharmaceutical sales data. Lancet Infect Dis 14:742-750

Wickham H (2016) ggplot2: elegant graphics for data analysis. SpringerVerlag, New York

Writer JH, Ryan JN, Keefe SH, Barb LB (2012) Fate of 4-nonylphenol and $17 \beta$-estradiol in the Redwood River of Minnesota. Environ Sci Technol 46:860-868

Ylla I, Romaní AM, Sebater S (2012) Labile and recalcitrant organic matter utilization by river biofilm under increasing water temperature. Microb Ecol 64:593-604

Zhang X, Li Y, Liu B, Wang J, Feng C (2014) The effects of estrone and $17 \beta$-estradiol on microbial activity and bacterial diversity in an agricultural soil: sulfamethoxazole as a co-pollutant. Ecotoxicol Environ Saf 107:313-320

Żur J, Piński A, Marchlewicz A, Hupert-Kocurek K, Wojcieszyńska D, Guzik U (2018) Organic micropollutants paracetamol and ibuprofen: toxicity, biodegradation, and genetic background of their utilization by bacteria. Environ Sci Pollut Res 25:21498-21524

Zuur AF, Ieno EN, Elphick CS (2010) A protocol for data exploration to avoid common statistical problems. Methods Ecol Evol 1:3-14

Publisher's note Springer Nature remains neutral with regard to jurisdictional claims in published maps and institutional affiliations. 